\title{
Pre-school nutrition-related behaviours at home and early childhood education services: findings from the Growing Up in New Zealand longitudinal study
}

\author{
Sarah Gerritsen ${ }^{1, *}$, Sarah E Anderson ${ }^{2}$, Susan MB Morton ${ }^{3}$ and Clare R Wall ${ }^{4}$ \\ ${ }^{1}$ School of Population Health, Faculty of Medical and Health Sciences, University of Auckland, Private Bag 92019, \\ Auckland, New Zealand: ${ }^{2}$ College of Public Health, The Ohio State University, Columbus, OH, USA: ${ }^{3}$ Centre for \\ Longitudinal Research, University of Auckland, Auckland, New Zealand: ${ }^{4}$ Department of Nutrition and Dietetics, \\ University of Auckland, Auckland, New Zealand
}

Submitted 28 August 2017: Final revision received 27 November 2017: Accepted 5 December 2017: First published online 5 February 2018

\begin{abstract}
Objective: Pre-school nutrition-related behaviours influence diet and development of lifelong eating habits. We examined the prevalence and congruence of recommended nutrition-related behaviours (RNB) in home and early childhood education (ECE) services, exploring differences by child and ECE characteristics. Design: Telephone interviews with mothers. Online survey of ECE managers/head teachers.

Setting: New Zealand.

Subjects: Children ( $n$ 1181) aged 45 months in the Growing Up in New Zealand longitudinal study.

Results: A mean 5.3 of 8 RNB were followed at home, with statistical differences by gender and ethnic group, but not socio-economic position. ECE services followed a mean 4.8 of $8 \mathrm{RNB}$, with differences by type of service and health-promotion programme participation. No congruence between adherence at home and in ECE services was found; half of children with high adherence at home attended a service with low adherence. A greater proportion of children in deprived communities attended a service with high adherence, compared with children living in the least deprived communities (20 and $12 \%$, respectively).

Conclusions: Children, across all socio-economic positions, may not experience RNB at home. ECE settings provide an opportunity to improve or support behaviours learned at home. Targeting of health-promotion programmes in high-deprivation areas has resulted in higher adherence to RNB at these ECE services. The lack of congruence between home and ECE behaviours suggests health-promotion messages may not be effectively communicated to parents/ family. Greater support is required across the ECE sector to adhere to RNB and promote wider change that can reach into homes.
\end{abstract}

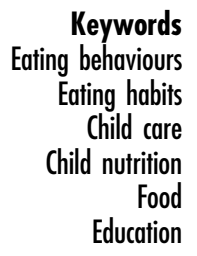

Early childhood is widely regarded as the ideal time to develop behaviours that assist with lifelong healthy eating patterns. Eating habits and food preferences are becoming established in the pre-school years and early childhood is characterized by 'high plasticity' and 'rapid transitions' that can effect behavioural change ${ }^{(1)}$. Parents and caregivers have a high degree of control over a child's food environment and a young child's dietary pattern and behaviours are therefore easier to influence than older children's and adults'. Additionally, many eating behaviours have been found to track from infancy to pre-school ${ }^{(2)}$, early childhood through childhood $^{(3)}$, from childhood to adolescence $^{(4)}$ and into adulthood ${ }^{(5)}$, confirming the importance of developing healthy behaviours early in life.
Families are a key social environment for the development of eating patterns and food preferences ${ }^{(6,7)}$. Several behaviours that occur in the home have been found to be positively associated with a healthy diet in early childhood: eating breakfast at home ${ }^{(8-10)}$; eating together as a family ${ }^{(11)}$; positive parental role modelling ${ }^{(12-14)}$; encouraging balance and variety ${ }^{(15)}$; and not watching television or using screens while eating ${ }^{(16)}$. Furthermore, there is evidence that some of these recommended behaviours may protect against the development of child overweight and obesity ${ }^{(17-19)}$.

Nutrition-related behaviours are embedded within a family's socio-economic context and influenced by the resources available to them ${ }^{(20)}$. The New Zealand Health 
Survey found significant socio-economic differences in recommended nutrition-related behaviours (RNB) and dietary intake for children aged $2-14$ years: those living in areas of high deprivation were 2.5 times more likely to have eaten breakfast at home fewer than five days in the past week, $2 \cdot 8$ times more likely to have eaten fast food three or more times in the past week, 3.5 times more likely to have had three or more fizzy drinks in the past week and $20 \%$ less likely to have met the daily vegetable and fruit intake recommendation compared with children living in the least deprived areas ${ }^{(21)}$. Children living in areas of high deprivation in New Zealand are three times more likely than children living in areas of low deprivation to be classified as obese based on their body mass, with one in five children in areas of high deprivation in the obese category $^{(21)}$.

For children with less-than-optimal home nutrition environments, out-of-home early childhood education (ECE) may provide an opportunity to ameliorate or buffer preferences and behaviours learned at home ${ }^{(22)}$. As the majority of young children in high-income countries are now enrolled in a day care centre or kindergarten prior to formal schooling, these ECE settings have become an important component of children's food and nutrition environments ${ }^{(20)}$. Systematic reviews have found that positive changes in young children's eating behaviours occur when ECE teachers engage in mealtime practices promoting self-regulation and use role modelling, although the lack of high-quality studies made it difficult to define exactly which mealtime practices should be recommended ${ }^{(23)}$. Current guidelines for early education services in New Zealand ${ }^{(24)}$, Australia ${ }^{(25)}$, the $\mathrm{USA}^{(26)}$ and the $\mathrm{UK}^{(27)}$ consider the following nutrition-related behaviours to be 'best practice': staff sit with children while they eat and eat the same food as children; staff talk to children about food at mealtimes; staff promote water consumption and encourage children to try unfamiliar foods; and staff never hurry children to finish eating, never use food as a reward and never restrict or deny food as a punishment. Nutrition concepts learnt in early education environments (e.g. the health benefits from eating fruit and vegetables) are often discussed by children at home and can impact family eating behaviours and practices ${ }^{(28)}$. In addition, several studies have reported positive nutritional outcomes when children grow fruit and vegetables, and prepare, cook or bake food in the early education setting ${ }^{(29-32)}$. A recent study found the most important RNB for improving children's dietary intake in childcare centres were educators' modelling, nutrition education and not using food as a reward ${ }^{(33)}$.

Barriers to effective communication and sharing of health-promotion messages between home and ECE settings may result in a lack of concordance between parent and teacher behaviours ${ }^{(34)}$. Ecological systems theory, originally proposed by Bronfenbrenner ${ }^{(35)}$, describes the interrelationship between the home and ECE environment as a 'mesosytem' influencing child development. Most child development research considers concordance in the mesosystem of home and early education to be advantageous for child development (e.g. when home cultural practices and language are reflected and celebrated within the early education service, then children feel accepted and thrive). However, as described above, concordance is not always preferable if a high-quality ECE service is providing positive experiences, or quality food for example, that is not available within the home. Gubbels et al. state that quantitative studies are required that explore the mesosystem created by interactions between the home and early education to further elucidate the effect of environments on child nutrition and activity behaviours ${ }^{(36)}$.

The present paper describes parent and teacher adherence to RNB for a sample of New Zealand children in both their home and ECE settings, investigating differences by child demographics and ECE service characteristics. We further explore the extent to which adherence is similar or dissimilar across the two settings to see if children who experience home environments with low adherence to RNB attend a health-promoting early education environment, which may buffer or ameliorate their home experiences. Previous research analysing menus collected from New Zealand early education services found greater alignment with nutrition guidelines when services were located in areas of high deprivation ${ }^{(37)}$. Accordingly, we hypothesize that RNB will be more prevalent in ECE services in areas of high deprivation and that this may have a potential influence on adherence to RNB at home (i.e. greater concordance between settings for children living in areas of high deprivation).

\section{Methods}

\section{Data sources}

The present study utilizes data from two sources: the Growing Up in New Zealand (GUiNZ) longitudinal study $^{(38)}$ and the Kai Time in ECE survey ${ }^{(39)}$. GUiNZ is the largest longitudinal study in New Zealand, following the health and development of a cohort of children born in 2009/10. The study recruited pregnant women from three district health board regions of New Zealand (Auckland, Counties Manukau and Waikato) ${ }^{(38)}$. The fourth data collection wave (DCW4) for GUiNZ was collected via a telephone call between February 2013 and January 2014 with 6211 mothers when their child was 45 months of age, representing over $90 \%$ retention across the pre-school period $^{(40)}$. The GUiNZ cohort is broadly analogous to all New Zealand births over a similar time period, although slightly more ethnically and socio-demographically diverse $^{(41)}$. Kai Time in ECE was a sixty-five-item online survey of managers and head teachers of 257 licensed early education services in the same three district health board regions of New Zealand where the GUiNZ cohort 


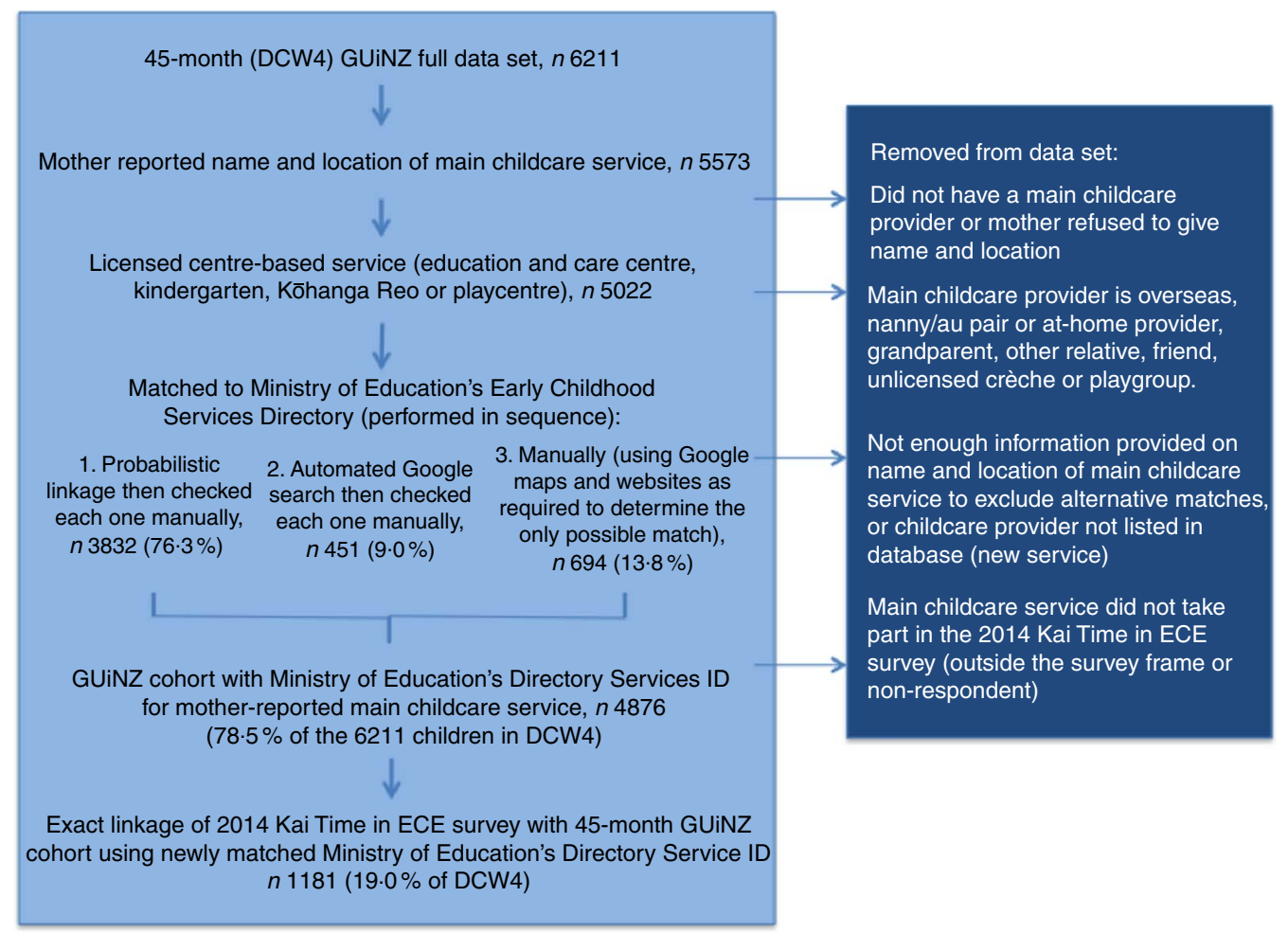

Fig. 1 Process used to match data from Growing Up in New Zealand (GUiNZ) with the Kai Time in ECE Survey to create the sub-sample for analyses (ECE, early childhood education; DCW4, fourth data collection wave)

was recruited, undertaken May to June 2014. All licensed services in this area were invited by email to take part. The $257(30 \cdot 3 \%)$ services that participated were broadly representative of all licensed services in the area when compared on several ECE service characteristics, except for Māori cultural immersion centres (Kōhanga Reo), which were under-represented in the survey ${ }^{(39)}$.

\section{Linkage of the data sets}

Data from the two sources were matched to create a sub-sample of 1181 children whose main childcare provider as reported by the mother in DCW 4 had taken part in the Kai Time in ECE survey (Fig. 1). The matching process, described in Fig. 1, began with probabilistically matching of name and location provided by the mother in DCW4 with the name and location of services listed on the Ministry of Education's Early Childhood Services Directory (August 2013), with each match manually checked or corrected. Additional matches were performed manually using Google and the Directory (Fig. 1). The Directory Service ID were then exactly matched with the Directory Service ID in the Kai Time in ECE data set. In total, 1181 children from DCW4 were successfully matched to 218 early education services from Kai Time in ECE $($ mean $=5.4(\mathrm{SD} 3.7)$ children in each ECE, range $=1-22$ ). For analysis purposes, data were treated as cross-sectional; that is, assuming no change between data collection periods.

\section{Home variables}

During the GUiNZ DCW4 interview, mothers reported the frequency of eight RNB: (i) child eats breakfast daily; (ii) family sits together for main meal; (iii) mealtimes are seen as a time to talk to each other; (iv) mealtimes are never rushed; (v) child eats same food as parents for his/her main meal; (vi) child eats a variety of foods; (vii) family mealtimes are enjoyable; and (viii) screens/ television rarely or never on when child is eating. Response categories (indicated in Table 1) were dichotomized and summed to create a count out of 8 for adherence. Observations with missing data (refused or don't know responses) were excluded from relevant analyses $(n \leq 15)$. Additional child demographic data from the fifth GUiNZ data collection wave (gender, main ethnic group, socio-economic position, mother's employment), collected face-to-face with mothers in the home when the child was 54 months old, were matched to the sub-sample. Ethnic group was mother-reported main ethnic group that the child identifies with, using Statistics New Zealand Level 1 classification $^{(42)}$. Socio-economic position was ascribed using the New Zealand Deprivation Index (NZDep2013) based on home address ${ }^{(43)}$. NZDep2013 combines nine variables from the 2013 census to reflect eight dimensions of deprivation, assigning a score for each meshblock (small geographical unit containing approximately 60-110 people). Categories of NZDep2013 deciles describe households as being in the $30 \%$ least deprived areas 
(low deprivation) to the $30 \%$ most deprived areas (high deprivation). NZDep2013 has strong construct and criterion validity and is the most common measure of socioeconomic position in health research in New Zealand ${ }^{(43)}$.

\section{Early education variables}

The head teacher or manager who participated in the Kai Time in ECE survey reported the frequency of eight RNB: (i) staff sit with children while they eat; (ii) staff eat the same food as children; (iii) staff talk to children about food at mealtimes; (iv) staff never hurry children to finish eating; (v) staff promote water consumption; (vi) staff never use food as a reward or punishment by restricting or denying access to food; (vii) children make, bake or cook food regularly; and (viii) children participate in gardening activities. Response categories (indicated in Table 1) were dichotomized and summed to create a count out of 8 for adherence. Centre characteristics of type, district health board region, number of students enrolled, and proportion of Māori and Pacific students were taken from the ECE Service Directory. Teacher to child ratio, proportion of teachers fully qualified and participation in the Heart Foundation's Healthy Heart Award (HHA; a healthpromotion programme in early education services in New Zealand) were self-reported in the Kai Time in ECE survey.

\section{Statistical analyses}

The distribution of responses for RNB in the home and education settings was examined and output by child demographics and centre characteristics, respectively. A total of 6205 children with information on four or more of the home RNB were included in home analyses, and 257 early education centres contribute to analyses of the education setting. To minimize potential bias, the full data sets were used to estimate prevalence of RNB. Spearman correlations were used to examine associations between RNB in the home and education setting separately and then across the two settings where possible (for the four similar RNB variables across the two settings). The number of RNB in each setting was summed and associations were examined between number of RNB and sociodemographic characteristics. Demographics of the sub-sample children (n 1181) were also compared with those of the full DCW4 GUiNZ cohort to estimate representativeness of the data.

Generalized linear models and $\chi^{2}$ tests were used to determine statistically significant differences in number of RNB by demographic characteristics. The matched sub-sample was used to examine the interrelationship of children's exposure to RNB across home and education settings. Children were categorized as having low $(\leq 4)$, moderate (5-6) or high (7-8) adherence to RNB in the home and, separately, the education setting. We cross-tabulated RNB category at home and school, overall and by NZDep2013 category. The $\chi^{2}$ test was used to identify statistically significant differences. An $\alpha$ level of 0.05 was used for all statistical tests. Data were analysed using the statistical software packages STATA version SE/13.1 and SAS version 9.3 .

\section{Results}

\section{Nutrition-related behaviours at bome}

Almost all children at 45 months of age were reported by their mother to eat breakfast at home every day, and three out of every four children to eat a wide variety of foods, sit with their family to eat their main meal every day, and always or mostly eat the same foods as their parents (Table 1). Just over half reported that mealtimes were seen as a chance to talk to each other and a similar proportion found family mealtimes enjoyable. Less than half of children rarely or never watched screens while eating, or were never rushed while eating at home (Table 1). All of the home $\mathrm{RNB}$, except for never having rushed mealtimes, were positively correlated with one another at $P<0.0001$. For comparability with the smaller set of data on the education setting, we only report correlations of $r=0.15$ or larger here: having main meals together as a family daily was positively correlated with children eating the same foods as parents $(r=0 \cdot 20)$ and mealtimes being seen as a time to talk $(r=0 \cdot 18)$; the child eating a variety of foods was correlated with eating the same foods as parents $(r=0.33)$ and mealtimes being enjoyable $(r=0.20)$; and mealtimes being enjoyable was also correlated with mealtimes being seen as a time to talk $(r=0 \cdot 25)$. Never having the television on when the child was eating was correlated with mealtimes being seen as a time to talk $(r=0 \cdot 16)$. Overall, the average number of home RNB was 5.3 out of 8 , with small but statistically significant differences by gender and ethnic group, but not socio-economic position (see online supplementary material, Table S1).

\section{Nutrition-related behaviours at licensed childcare services}

The most common nutrition-related behaviours in ECE settings were staff promoting water consumption, never using food as a reward or punishment, and staff sitting with children while they ate (Table 1). Two out of every three early education services reported baking or cooking with children at least weekly, and a similar proportion gardened with children at least weekly. The least followed RNB in the early education setting were staff always or mostly eating the same food as children, always talking to children about food at mealtimes, and never hurrying children to finish eating (Table 1). Staff always talking to children about food was positively correlated with four variables: encouraging water consumption $(r=0 \cdot 27)$; always sitting with children to eat $(r=0 \cdot 26)$; always or mostly eating the same food as children $(r=0 \cdot 16)$; and gardening at least weekly $(r=0 \cdot 16)$. Additionally, staff always sitting with children to eat was positively correlated 
Table 1 Recommended nutrition-related behaviours adhered to in home and early education settings for 45-month-old New Zealand children

\begin{tabular}{|c|c|c|c|c|c|}
\hline Home behaviours* & $n$ & $\%$ & Early education behaviours $\dagger$ & $n$ & $\%$ \\
\hline Family sit together for main meal every day ${ }^{a}$ & 4880 & $78 \cdot 7$ & Staff sit with children while they eat ${ }^{\mathrm{a}}$ & 206 & $80 \cdot 2$ \\
\hline Child eats same food as parents ${ }^{b}$ & 4957 & 79.9 & Staff eat and drink the same things as children ${ }^{b}$ & 67 & $26 \cdot 1$ \\
\hline Mealtimes are seen as a time to talk to each other ${ }^{c}$ & 3457 & $55 \cdot 8$ & Staff talk to children about food at mealtimes ${ }^{a}$ & 127 & $49 \cdot 4$ \\
\hline Mealtimes are never rushed ${ }^{\mathrm{d}}$ & 2432 & $39 \cdot 2$ & Staff never hurry children to finish eating ${ }^{\mathrm{c}}$ & 101 & $39 \cdot 3$ \\
\hline Child eats a variety of foods ${ }^{e}$ & 4993 & 80.5 & Staff encourage or promote water consumption ${ }^{a}$ & 217 & 84.4 \\
\hline Family mealtimes are enjoyable for everyone ${ }^{c}$ & 3579 & $57 \cdot 7$ & Staff never use food as a reward or deny food as a punishment ${ }^{d}$ & 239 & $93 \cdot 0$ \\
\hline Child eats breakfast every day ${ }^{a}$ & 5863 & 94.5 & Children make, bake or cook food at least weekly ${ }^{\mathrm{e}}$ & 140 & $58 \cdot 8$ \\
\hline Television is rarely on when child is eating ${ }^{f}$ & 2875 & $46 \cdot 3$ & Children garden at least weekly & 127 & 59.9 \\
\hline Total children & 6205 & 100 & Total services & 257 & 100 \\
\hline
\end{tabular}

*Data from the Growing Up in New Zealand 45-month data collection wave (DCW4). Missing data $(n \leq 15)$ were excluded from individual home variable analyses. ${ }^{\text {a }}$ Reported as number of days per week; binary variable defined as $7 \mathrm{v} .<7$. ' $R e s p o n s e$ options were 'always', 'almost always', 'sometimes', 'almost never' and 'never'; binary variable defined as 'always' and 'almost always' $v$. other responses. 'Response options were 'never', 'occasionally', 'quite often' and 'mostly'; binary variable defined as 'mostly' $v$. other responses. 'Response options were 'never', 'occasionally', 'quite often' and 'mostly'; binary variable defined

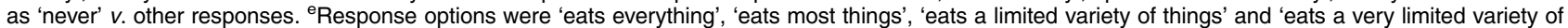
things'; binary variable defined as 'eats everything' or 'eats most things' $v$. other responses. 'Response options were 'always', 'almost always', 'sometimes' and 'almost never', 'never'; binary variable defined as 'never' or 'almost never' $v$. other responses.

tData from Kai Time in ECE online survey of early childhood education (ECE) services; manager-reported about staff behaviours relevant to 3-and 4-year-olds. Imputation was conducted for fifteen services with missing nutrition behaviour variables, based on proportionate responses by type of service. ${ }^{2}$ Response options were 'always', 'most of the time', 'sometimes', 'rarely' and 'never'; binary variable defined as 'always' $v$. other responses. 'Response options were 'always', 'most of the time', 'sometimes', 'rarely' and 'never'; binary variable defined as 'always' and 'most of the time' $v$. other responses. 'Response options were 'always', 'most of the time', 'sometimes', 'rarely' and 'never'; binary variable defined as 'never' $v$. other responses. 'Response options were 'never', 'some staff members', 'most staff members' and 'all staff members'; binary variable defined as 'never' $v$. other responses. 'Response options were 'daily', 'weekly but not every day', 'monthly but not every week, 'a few times a year' and 'very rarely'; binary variable defined as 'daily' and 'weekly but not every day' $v$. other responses.

with promoting water consumption $(r=0 \cdot 16)$ and gardening at least weekly was positively correlated with baking at least weekly $(r=0 \cdot 22)$. The average number of RNB followed by early education services was $4 \cdot 8$ out of 8 (minimum 0, maximum 8 ). Kindergartens had proportionately greater adherence to RNB (mean 5.5 RNB), compared with community-based centres (4.7), privately owned centres (4.8) and playcentres (4.3). Services enrolled in the Heart Foundation's HHA had higher average adherence to recommended behaviours (mean of 5.3 compared with $4 \cdot 7$, but with large variation; see online supplementary material, Table S2).

\section{Concordance between nutrition behaviours in bome and early education settings}

Demographics for the cohort of children in GUiNZ ( $n$ 6211) were compared with those of the sub-sample of children used in analyses comparing home and early education nutrition-related behaviours ( $n$ 1181). The children in the sub-sample all lived in New Zealand and all attended licensed out-of-home group-based childcare at 45 months (compared with 95.2 and $77.8 \%$ of the full cohort, respectively). Children in the sub-sample attended licensed childcare for $1.3 \mathrm{~h} /$ week less than did the full cohort. Mothers of children in the sub-sample were not statistically more likely to be in paid employment. They worked on average $28.8 \mathrm{~h} /$ week, with $34 \%$ of mothers working $40 \mathrm{~h}$ or more/week. The homes of children in the sub-sample were slightly less likely to be in areas of high neighbourhood deprivation, but there was still a sizeable number in each of the socio-economic position categories with which to conduct stratified analyses (see online supplementary material, Table S3).
There were no correlations in adherence between settings for the four RNB for which similar variables were collected in both settings, i.e. parent/teacher sitting with child for meals, parent/teacher eating the same food as child, parent/teacher talking to child at meals and parent/ teacher not rushing child to eat ( $\rho$ close to 0 for each pair). There was also no relationship between the number of RNB followed in a child's home and early education environment ( $P=0 \cdot 17$; Table 2$)$. Almost half of children from homes with high adherence to RNB ( 7 or 8 out of 8 RNB) attended an early education service with low adherence to RNB (Table 2).

\section{Nutrition-related behaviours by bousebold socio-economic position}

In the full cohort, adherence to RNB at home did not differ by socio-economic status $(P=0 \cdot 10)$. Three of ten children had low adherence to nutrition-related behaviours in the home and fewer than one in ten had high adherence to nutrition-related behaviours at home (7.4\%). However, one in five children living in areas of high deprivation attended an early education service with high adherence to RNB; a higher proportion than among children living in areas of low deprivation ( $P=0 \cdot 04$; Fig. 2 ). Children living in areas of high deprivation with poor adherence to RNB were more likely to attend an early education service following RNB when compared with similarly deprived children with high adherence at home (24.8 and $14.0 \%$, respectively, $P=0.01$; Fig. 2). There was no statistically significant difference for children living in areas of low household deprivation, who were equally as likely to attend an early education service with low adherence to RNB irrespective of home behaviours $(P=0 \cdot 87)$. 
Table 2 Adherence to recommended nutrition-related behaviours (RNB) for 45-month-old children ${ }^{*}$ in the home and early childhood education (ECE) settings

\begin{tabular}{|c|c|c|c|c|c|c|c|c|}
\hline \multirow[b]{3}{*}{ Adherence to RNB at home } & \multicolumn{8}{|c|}{ Adherence to RNB in ECE service } \\
\hline & \multicolumn{2}{|c|}{$\begin{array}{c}\text { Low } \\
(\leq 4 \text { RNB })\end{array}$} & \multicolumn{2}{|c|}{$\begin{array}{l}\text { Moderate } \\
\text { (5-6 RNB) }\end{array}$} & \multicolumn{2}{|c|}{$\begin{array}{c}\text { High } \\
\text { (7-8 RNB) }\end{array}$} & \multicolumn{2}{|c|}{ Total } \\
\hline & $n$ & $\%$ & $n$ & $\%$ & $n$ & $\%$ & $n$ & $\%$ \\
\hline Low ( $\leq 4 \mathrm{RNB})$ & 130 & 39.6 & 144 & 43.9 & 54 & $16 \cdot 5$ & 328 & $27 \cdot 8$ \\
\hline Moderate (5-6 RNB) & 207 & 38.5 & 243 & $45 \cdot 2$ & 88 & $16 \cdot 4$ & 538 & $45 \cdot 6$ \\
\hline High (7-8 RNB) & 148 & $47 \cdot 0$ & 122 & $38 \cdot 7$ & 45 & $14 \cdot 3$ & 315 & $26 \cdot 7$ \\
\hline Total & 485 & $41 \cdot 1$ & 509 & 43.1 & 187 & $15 \cdot 8$ & 1181 & $100 \cdot 0$ \\
\hline
\end{tabular}

*In a sub-sample of the Growing Up in New Zealand cohort for whom information was collected from their main childcare provider at 45 months of age in the 2014 Kai Time in ECE survey.

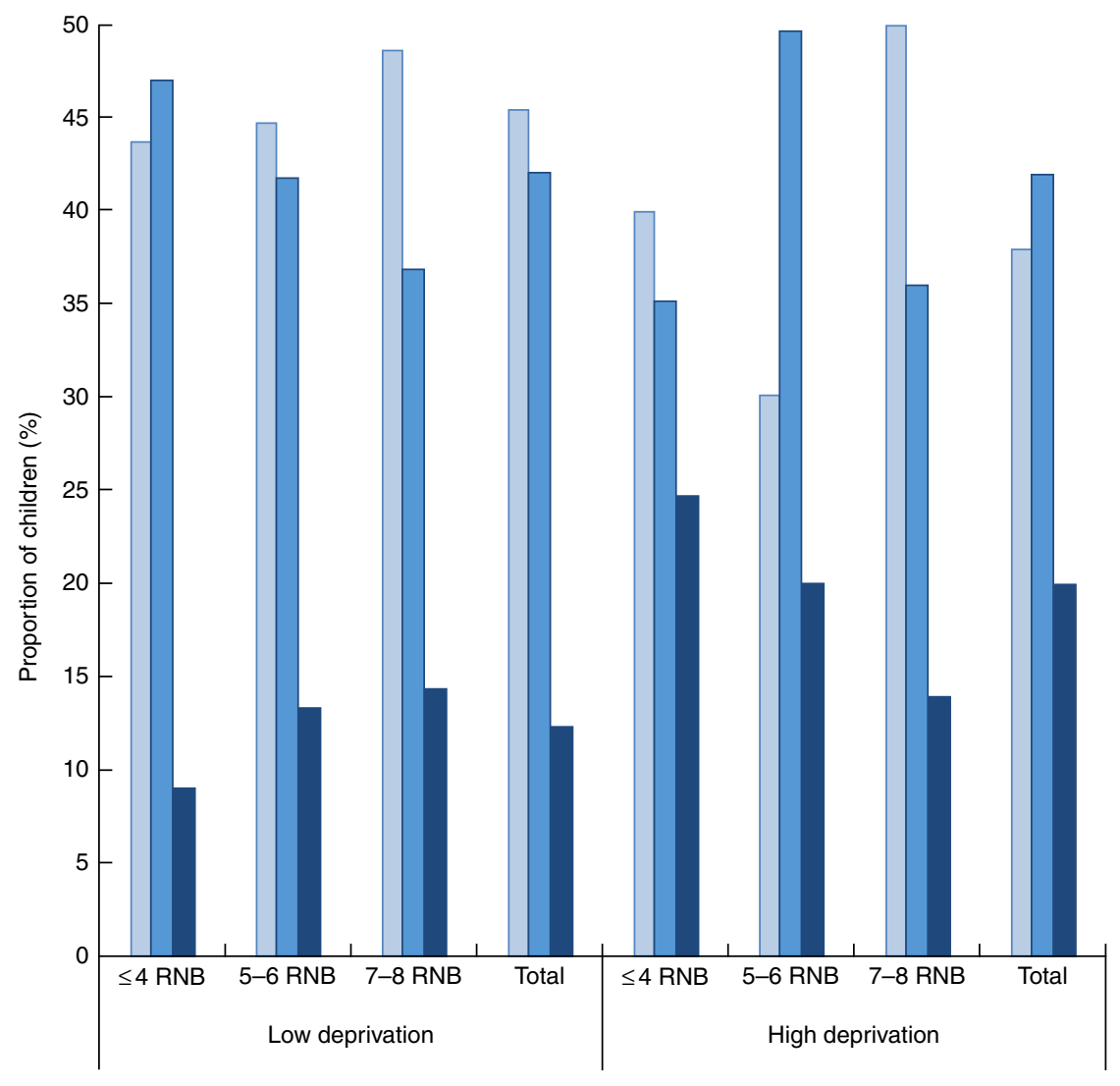

Adherence to RNB at home

Fig. 2 (colour online) Adherence to recommended nutrition-related behaviours (RNB) at home by socio-economic status and adherence to RNB by early childhood education (ECE) service ( $\square$, $\leq 4$ RNB; $\square, 5-6$ RNB; $\square, 7-8$ RNB) in a sub-sample of the Growing Up in New Zealand cohort for whom information was collected from their main childcare provider at 45 months of age in the 2014 Kai Time in ECE survey. Socio-economic status was measured using the New Zealand Deprivation Index (NZDep2013) as low $=$ deciles $1-3 \quad(30 \%$ least deprived neighbourhoods in New Zealand) and high $=$ deciles $8-10$ (30\% most deprived neighbourhoods in New Zealand). NZDep2013 data for households were missing for thirty-seven children in the matched subsample $(3.1 \%)$ and therefore excluded from these analyses. Pearson $\chi_{(4)}^{2}=6.36, P=0.17$ for all children; $\chi_{(4)}^{2}=3.33, P=0.50$ for low deprivation; $\chi_{(4)}^{2}=12 \cdot 79, P=0.01$ for high deprivation

\section{Discussion}

The present comparative analysis of adherence to RNB in the home and childcare environments of 1181 children of pre-school age found little concordance between the two settings. Children living in homes following RNB were no more likely to attend early education services adhering to
$\mathrm{RNB}$, and half of children from homes with high adherence to RNB (irrespective of socio-economic position) attended a service with low adherence. It is a commonly expressed frustration of early education staff (including in New Zealand ${ }^{(39)}$ ) that many parents do not follow best nutrition-related practices at home ${ }^{(34,44-47)}$. For the staff in early education services with high adherence to RNB, 
only one out of every four children in their care ( $n$ 45/187, $24 \%$ ) experienced high adherence to RNB at home. However, it was a minority of services that had high adherence themselves and there was wide variation across the sector in adherence to the 'best practice' of RNB. Notably, the majority of caregivers in both settings reported that children were sometimes rushed to finish eating. Parents and teachers may find it difficult to schedule seated, conversational and slow-paced lunch and snack times, but rushing a child when eating can override internal satiety cues and lead to overeating, or not eating enough quantity or variety of foods which exacerbates fussy eating. The US Academy of Nutrition and Dietetics warns against a non-responsive feeding approach (which includes both pressuring a child to eat and uninvolved feeding) as this is associated with excess weight gain $^{(48)}$.

It is possible that ECE staff in New Zealand are not aware of RNB as there are no mandated standards in the sector, only recommendations promoted by the Heart Foundation (with $20 \%$ of ECE services subscribing to its communications) ${ }^{(24)}$. There is also limited inclusion of nutrition in teacher training across the ECE sector in New Zealand and nutrition education opportunities for ECE staff are sparse ${ }^{(49)}$. A possible way to achieve more professional development in nutrition for ECE staff would be to incorporate aspects of the Heart Foundation's HHA into widespread teacher training and professional practice, and/or the expansion of health-promotion programmes such as the HHA or Under 5 Energize $^{(50)}$, which promote knowledge transfer to staff. The HHA is currently voluntary and targeted to early education services in areas of high deprivation ${ }^{(51)}$. As well as a menu improvement component, the programme contains training for staff on eating behaviours, including water promotion, seated mealtimes and talking to children about food ${ }^{(51)}$. Interventions for the prevention of obesity, such as the HHA, have been proved to have the greatest effect when targeting children at high risk (i.e. children already overweight and of lower socio-economic status) ${ }^{(52)}$ and intuitively it is a commendable idea to target services where there is the greatest need to reduce inequity. However, the present study has found a need for greater support across the ECE sector to adhere with RNB, as over $40 \%$ of children attended childcare services with low adherence to the guidelines and a further $40 \%$ attended services with only moderate rather than high adherence, irrespective of household deprivation level.

In contrast to findings from the New Zealand Health Survey ${ }^{(21)}$, GUiNZ children living in areas of high deprivation were not less likely to follow RNB at home. However, children living in deprived communities were significantly more likely to attend an early childcare service that followed recommended practices. There was therefore potentially an ameliorating or buffering effect for a quarter (24.8\%) of children living in areas of high deprivation who experienced low adherence at home but attended an early childhood service with high adherence to RNB. By comparison, this occurred for only $9 \cdot 1 \%$ of children living in areas of low deprivation with a low number of $\mathrm{RNB}$ at home. Interestingly, children living in homes with low adherence to RNB in areas of high deprivation were more likely to attend an early education service with high adherence to RNB when compared with similarly deprived children with high adherence at home. This may be due to the early education service responding to needs of children in their care, i.e. staff see that nutrition is a learning need for children attending and respond by improving the nutrition-related behaviours within their service (e.g. through engagement with the Heart Foundation's HHA).

The lack of congruence between behaviours in the home and the ECE setting suggests that parents most likely do not choose an ECE service that reflects home adherence to $\mathrm{RNB}$, and that there are barriers to effective communication and sharing of health-promotion messages between home and ECE settings. A recent review of parental childcare decision making in the USA found that although 'health and safety' often featured in parents' decisions, this was due to concerns about 'safety' as opposed to nutrition or dietary practices which were generally not listed as key factors in decision making ${ }^{(53,54)}$. Mothers of the children in the present study reported that they felt they had a choice when deciding which type of early childhood education to use ( $n$ 1040, 91.0\% in DCW5). However, the top three reasons for choosing their child's main childcare provider were unrelated to health or nutrition: location (15.8\%), reputation of childcare provider $(11.2 \%)$, and that it best suits work or studies $(10.0 \%)^{(40)}$. Barraclough and Smith found that high levels of parental choice and satisfaction with childcare services were not related to research-based measures of quality in early education services and they suggest that "parents probably do not have knowledge to effectively evaluate quality and make critical choices, ${ }^{(55)}$. It is therefore incumbent on the government to ensure all ECE services have adequate information and training to follow RNB and monitor adherence to quality standards. Further research on the barriers ECE staff face in effective communication with parents to ensure consistency in RNB across settings would be helpful.

The strength of the present study is that it utilizes information from a sizeable subset of children involved in the largest longitudinal cohort study in New Zealand, for whom we had additional information from each child's main childcare service. Previous research comparing nutrition-related aspects of the home and early education or childcare environments for young children has generally focused on differences in dietary intake between the two environments ${ }^{(56)}$ and the present study is the first we are aware of that compares a range of nutrition-related behaviours. Limitations of the study include that behaviours were self-reported and thus potentially affected by social desirability or recall bias. Also, the wording of questions in 
the home was child-specific and in the ECE was teacher/ staff-specific, and not all nutrition-related behaviours were included in GUiNZ and Kai Time in ECE, both of which covered a wider range of topics. Future research focusing on eating behaviours in the home should also include robust measures of parental role modelling ${ }^{(6,57)}$, routines ${ }^{(19,58,59)}$ and parental feeding styles ${ }^{(60-62)}$ as these are emerging in the literature as important predictors of dietary and body size outcomes. A final limitation to note is the modest response rate in the online Kai Time in ECE survey of $30 \%$. Although the Kai Time sample was proportionately similar on a range of centre characteristics when compared with the total population of licensed childcare services within the regions surveyed, we cannot be certain that the Kai Time data are unaffected by non-response bias ${ }^{(39)}$.

\section{Conclusion}

The present paper has explored adherence to RNB within the home and centre-based childcare in a large sample of children aged 45 months. Nutrition-related behaviours with the lowest adherence in the home were eating with the television on and hurrying children to finish eating. Less than half of ECE services followed recommendations for role modelling healthy eating, talking to children about food during mealtimes and not hurrying children to finish eating. Only a small number of children (4\%) experienced high adherence to RNB in both their home and early education environment, and no relationships were found between adherence to RNB in a child's home and early education service. Children from communities with high levels of deprivation were significantly more likely to attend an early childcare service following recommended practices; a quarter of children living in disadvantaged communities experiencing low adherence to RNB at home attended an early education service with high adherence. Kindergartens (who have a higher proportion of fully trained staff) and ECE services with a Heart Foundation HHA had significantly higher adherence to RNB. This research points to a need for widespread health promotion across the ECE sector to provide healthier environments for young children.

\section{Acknowledgements}

Acknowledgements: The authors thank the Growing Up in New Zealand families and the managers/head teachers who participated in the Kai Time in ECE survey, and Catherine Yeunhyang Choi, Avinesh Pillai and Philip Vlaskovsky for statistical advice and assistance merging data sets. The Growing Up in New Zealand study was designed and conducted by the Growing Up in New Zealand Study Team, led by the University of Auckland. The authors acknowledge the contributions of the original study investigators: Susan M.B. Morton, Polly E. Atatoa Carr, Cameron C. Grant, Arier C. Lee, Dinusha K. Bandara, Jatender Mohal, Jennifer M. Kinloch, Johanna M. Schmidt, Mary R. Hedges, Vivienne C. Ivory, Te Kani R. Kingi, Renee Liang, Lana M. Perese, Elizabeth Peterson, Jan E. Pryor, Elaine Reese, Elizabeth M. Robinson, Karen E. Waldie and Clare R. Wall. The views reported in this paper are those of the authors and do not necessarily represent the views of the Growing Up in New Zealand Investigators. Financial support: The Kai Time in ECE survey and data analyses for this manuscript were funded by a University of Auckland Doctoral Scholarship and Gravida: National Centre for Growth and Development Postgraduate Scholarship. Growing Up in New Zealand has been funded by the New Zealand Ministries of Social Development, Health, Education and Justice; the former Ministry of Science Innovation and the former Department of Labour (now both part of the Ministry of Business, Innovation and Employment); the former Ministry of Pacific Island Affairs (now the Ministry for Pacific Peoples); the former Ministry of Women's Affairs (now the Ministry for Women); the Department of Corrections; the Families Commission (now known as the Social Policy Evaluation and Research Unit); Te Puni Kokiri; New Zealand Police; Sport New Zealand; Housing New Zealand Corporation; the former Mental Health Commission (now part of the Office of the Health and Disability Commissioner); The University of Auckland; and Auckland UniServices Limited. Other support for the study has been provided by the Health Research Council of New Zealand, Statistics New Zealand, the Office of the Children's Commissioner and the Office of Ethnic Affairs (now the Office of Ethnic Communities). Funders had no role in the design, analysis or writing of this article. Conflict of interest: None. Authorship: S.G., C.R.W. and S.M.B.M. conceived of the study. S.G. collected data from the early education service managers and head teachers, matched the data sets, conducted statistical analyses of the ECE data and the matched data set, and drafted the manuscript. S.E.A. analysed data from the Growing Up in New Zealand cohort and assisted with interpretation. S.M.B.M. is the principal investigator and C.R.W. is the nutrition domain lead for the Growing Up in New Zealand longitudinal study. All authors reviewed draft manuscripts and approved the final manuscript. Ethics of human subject participation: This study was conducted according to the guidelines laid down in the Declaration of Helsinki and all procedures involving human subjects were approved by the Ministry of Health's Northern Regional Y Committee (for the Growing Up in New Zealand study) and the University of Auckland's Human Ethics Committee (for the Kai Time in ECE study). Written consent was obtained from all subjects.

\section{Supplementary material}

To view supplementary material for this article, please visit https://doi.org/10.1017/S1368980017004116 


\section{References}

1. Birch LL \& Anzman SL (2010) Learning to eat in an obesogenic environment: a developmental systems perspective on childhood obesity. Child Dev Perspect 4, 138-143.

2. Lioret S, Betoko A, Forhan A et al. (2015) Dietary patterns track from infancy to preschool age: cross-sectional and longitudinal perspectives. J Nutr 145, 775-782.

3. Wall CR, Thompson JM, Robinson E et al. (2013) Dietary patterns of children at 3.5 and 7 years of age: a New Zealand birth cohort study. Acta Paediatr 102, 137-142.

4. Emmett PM, Jones LR \& Northstone K (2015) Dietary patterns in the Avon Longitudinal Study of Parents and Children. Nutr Rev 73, Suppl. 3, 207-230.

5. Lipsky LM, Haynie DL, Liu D et al. (2015) Trajectories of eating behaviors in a nationally representative cohort of US adolescents during the transition to young adulthood. Int J Behav Nutr Phys Act 12, 138.

6. Ventura AK \& Birch LL (2008) Does parenting affect children's eating and weight status? Int J Behav Nutr Phys Act 5, 15

7. Delormier T, Frohlich KL \& Potvin L (2009) Food and eating as social practice - understanding eating patterns as social phenomena and implications for public health. Sociol Health Illn 31, 215-228.

8. Rampersaud GC, Pereira MA, Girard BL et al. (2005) Breakfast habits, nutritional status, body weight, and academic performance in children and adolescents. J Am Diet Assoc 105, 743-760.

9. Timlin MT \& Pereira MA (2007) Breakfast frequency and quality in the etiology of adult obesity and chronic diseases. Nutr Rev 65, 268-281.

10. Quigley R, Taylor R \& Scragg R (2007) Is Consuming Breakfast Important for Academic Performance, Maintaining a Healthy Body Weight, and Improving Nutrient Intake and Lifestyle Habits in Children? Wellington: Scientific Committee of Agencies for Nutrition Action.

11. Hammons AJ \& Fiese BH (2011) Is frequency of shared family meals related to the nutritional health of children and adolescents? Pediatrics 127, e1565-e1574.

12. Draxten M, Fulkerson JA, Friend S et al. (2014) Parental role modeling of fruits and vegetables at meals and snacks is associated with children's adequate consumption. Appetite $\mathbf{7 8}, 1-7$.

13. Pearson N, Biddle SJH \& Gorely T (2009) Family correlates of fruit and vegetable consumption in children and adolescents: a systematic review. Public Health Nutr 12, 267-283.

14. Brown R, Scragg R \& Quigley R (2008) Does the Family Environment Contribute to Food Habits or Behaviours and Physical Activity in Children? Wellington: Scientific Committee of Agencies for Nutrition Action.

15. Haszard J, Williams S, Skidmore P et al. (2012) Parental feeding practices are related to children's diet and weight. Obes Res Clin Pract 6, 48.

16. Marsh S, Ni Mhurchu C \& Maddison R (2013) The non-advertising effects of screen-based sedentary activities on acute eating behaviours in children, adolescents, and young adults. A systematic review. Appetite 71, 259-273.

17. Dubois L, Farmer A, Girard M et al. (2008) Social factors and television use during meals and snacks is associated with higher BMI among pre-school children. Public Health Nutr 11, 1267-1279.

18. Dubois L, Girard M \& Kent MP (2006) Breakfast eating and overweight in a pre-school population: is there a link? Public Health Nutr 9, 436-442.

19. Anderson SE \& Whitaker RC (2010) Household routines and obesity in US preschool-aged children. Pediatrics 125, 420-428.

20. Story M, Kaphingst KM, Robinson-O'Brien R et al. (2008) Creating healthy food and eating environments: policy and environmental approaches. Annu Rev Public Health 29, 253-272.
21. Ministry of Health (2016) Annual Update of Key Results 2015/16: New Zealand Health Survey. Wellington: Ministry of Health.

22. Story M, Kaphingst KM \& French S (2006) The role of child care settings in obesity prevention. Future Child 16, 143-168.

23. Ward S, Bélanger M, Donovan D et al. (2015) Systematic review of the relationship between childcare educators' practices and preschoolers' physical activity and eating behaviours. Obes Rev 16, 1055-1070.

24. Heart Foundation (2012) Fuelled llife Nutrition Guide for Early Childhood Education Services. Wellington: National Heart Foundation of New Zealand.

25. Department of Health, Australian Government (2013) Get Up \& Grow: Healthy Eating and Physical Activity for Early Childhood - Director/Coordinator Book. Canberra: Department of Health, Australian Government.

26. Department of Health and Human Services, Administration for Children and Families (2016) Head Start Program Performance Standards. Washington, DC: US Department of Health and Human Services.

27. Children's Food Trust (2012) Voluntary Food and Drink Guidelines for Early Years Settings in England - A Practical Guide. Sheffield: The Children's Food Trust.

28. Tysoe J \& Wilson C (2010) Influences of the family and childcare food environments on preschoolers' healthy eating. Australas J Early Child 35, 105-110.

29. Hersch D, Perdue L, Ambroz T et al. (2014) The impact of cooking classes on food-related preferences, attitudes, and behaviors of school-aged children: a systematic review of the evidence, 2003-2014. Prev Chronic Dis 11, E193.

30. Dawson A, Richards R, Collins C et al. (2013) Edible gardens in early childhood education settings in Aotearoa, New Zealand. Health Promot J Aust 24, 214-218.

31. DeCosta P, Møller P, Frøst MB et al. (2017) Changing children's eating behaviour - a review of experimental research. Appetite 113, 327-357.

32. Gubbels JS, Gerards SM \& Kremers SP (2015) Use of food practices by childcare staff and the association with dietary intake of children at childcare. Nutrients 7, 2161-2175.

33. Ward S, Blanger M, Donovan D et al. (2017) Association between childcare educators' practices and preschoolers' physical activity and dietary intake: a cross-sectional analysis. BMJ Open 7, 5 .

34. Dev DA, Byrd-Williams C, Ramsay S et al. (2017) Engaging parents to promote children's nutrition and health. Am J Health Promot 31, 153-162.

35. Bronfenbrenner U (1979) Ecology of Human Development: Experiments by Nature and Design. Cambridge MA: Harvard University Press.

36. Gubbels J, Van Kann D, de Vries N et al. (2014) The next step in health behavior research: the need for ecological moderation analyses - an application to diet and physical activity at childcare. Int J Behav Nutr Phys Act 11, 52.

37. Gerritsen S, Dean B, Wall CR et al. (2017) Do childcare menus meet nutrition guidelines? An analysis of the quantity, variety and quality of food provided in New Zealand Early Childhood Education services. Aust NZJ Public Health 41, 345-351.

38. Morton SM, Atatoa Carr PE, Grant CC et al. (2013) Cohort profile: growing up in New Zealand. Int J Epidemiol 42, 65-75.

39. Gerritsen S, Wall C \& Morton S (2016) Child-care nutrition environments: results from a survey of policy and practice in New Zealand early childhood education services. Public Health Nutr 19, 1531-1542.

40. Morton SMB, Grant CC, Berry SD et al. (2017) Now We Are Four: Describing the Preschool Years. Auckland: University of Auckland.

41. Morton SMB, Ramke J, Kinloch J et al. (2014) Growing Up in New Zealand cohort alignment with all New Zealand births. Aust N Z J Public Health 39, 82-87. 
42. Statistics New Zealand (2005) Statistical Standard for Ethnicity. Wellington: Statistics New Zealand.

43. Atkinson J, Salmond C \& Crampton P (2014) NZDep2013 Index of Deprivation User's Manual. Wellington: University of Otago.

44. Finnane J (2017) Exploring partnerships between early childhood educators and parents to promote healthy eating to children (Leaps Study). Master of Applied Science Research Thesis, Queensland University of Technology.

45. Lynch M \& Batal M (2011) Factors influencing childcare providers' food and mealtime decisions: an ecological approach. Child Care Pract 17, 185-203.

46. Needham L, Dwyer JJM, Randall-Simpson J et al. (2007) Supporting healthy eating among preschoolers: challenges for child care staff. Can J Diet Pract Res 68, 107-110.

47. Sisson SB, Smith CL \& Cheney M (2017) Big impact on small children: child-care providers' perceptions of their role in early childhood healthy lifestyle behaviours. Child Care Pract 23, 162-180.

48. Ogata BN \& Hayes D (2014) Position of the Academy of Nutrition and Dietetics: nutrition guidance for healthy children ages 2 to 11 years. J Acad Nutr Diet 114, 1257-1276.

49. Gerritsen S (2016) Nutrition education for early childhood managers, teachers and nursery cooks: a prerequisite for effective obesity prevention. Public Health 140, 56-58.

50. Rush E, Obolonkin V, Young L et al. (2017) Under 5 Energize: tracking progress of a preschool nutrition and physical activity programme with regional measures of body size and dental health at age of four years. Nutrients $\mathbf{9}$, E456.

51. Heart Foundation (2012) Healthy Heart Award for Early Childhood Education: Handbook. Auckland: National Heart Foundation of New Zealand.

52. Sisson SB, Krampe M, Anundson K et al. (2016) Obesity prevention and obesogenic behavior interventions in child care: a systematic review. Prev Med 87, 57-69.
53. Forry N, Tout K, Rothenburg L et al. (2013) Child Care Decision-Making Literature Review. Issue Brief OPRE Brief 2013-45. Washington, DC: Office of Planning, Research and Evaluation, Administration for Children and Families, US Department of Health and Human Services.

54. Perrin EM, Howard JB \& Ward DS (2016) In the absence of clear causation, casting a wider net for prevention. Pediatrics 138, e20162895.

55. Barraclough SJ \& Smith AB (1996) Do parents choose and value quality child care in New Zealand? Int J Early Years Educ 4, 5-26.

56. Briley ME, Jastrow S, Vickers J et al. (1999) Dietary intake at child-care centers and away: are parents and care providers working as partners or at cross-purposes? J Am Diet Assoc 99, 950-954.

57. Pinard CA, Yaroch AL, Hart MH et al. (2012) Measures of the home environment related to childhood obesity: a systematic review. Public Health Nutr 15, 97-109.

58. Anderson SE, Sacker A, Whitaker RC et al. (2017) Self-regulation and household routines at age three and obesity at age eleven: longitudinal analysis of the UK Millennium Cohort Study. Int J Obes (Lond) 41, 1459-1466.

59. Spagnola M \& Fiese BH (2007) Family routines and rituals: a context for development in the lives of young children. Infants Young Child 20, 4, 284-299.

60. Shloim N, Edelson LR, Martin N et al. (2015) Parenting styles, feeding styles, feeding practices, and weight status in 4-12 year-old children: a systematic review of the literature. Front Psychol 6, 1849.

61. Vollmer R \& Mobley AR (2013) Parenting styles, feeding styles, and their influence on child obesogenic behaviors and body weight. A review. Appetite 71, 232-241.

62. Sleddens EF, Gerards SM, Thijs C et al. (2011) General parenting, childhood overweight and obesity-inducing behaviors: a review. Int J Pediatr Obes 6, e12-e27. 